\title{
Synergistically Improved Physico-Mechanical Properties of Nanopolystyrene-Viton Rubber Blends
}

\section{ISSN: 2576-8840}

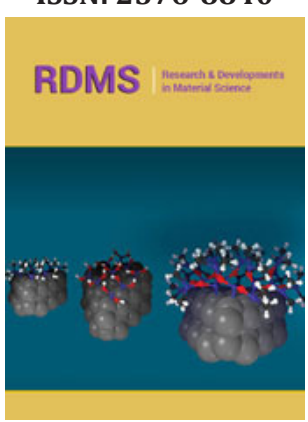

*Corresponding author: Satyendra Mishra, Department of Plastics Technology, University Institute of Chemical Technology, Kavayitri Bahinabai Chaudhari North Maharashtra University, Jalgaon-425001, India

Submission: 侮 May 10, 2019

Published: 偨 May 20, 2019

Volume 10 - Issue 5

How to cite this article: Pratibha $P$ Hansora D, Satyendra M. Synergistically Improved Physico-Mechanical Properties of Nanopolystyrene-Viton Rubber Blends. Res Dev Material Sci. 10(5). RDMS.000750.2019.

DOI: 10.31031/RDMS.2019.10.000750

Copyright@ Satyendra Mishra, This article is distributed under the terms of the Creative Commons Attribution 4.0 International License, which permits unrestricted use and redistribution provided that the original author and source are credited.

\section{Pratibha Patil, Hansora DP and Satyendra Mishra*}

Department of Plastics Technology, Kavayitri Bahinabai Chaudhari North Maharashtra University, India

\begin{abstract}
This research work represents the synergistic effect of nanopolystyrene (nPS) and viton rubber (VR) for the improvement in physico-mechanical properties of nPS-VR blends. The nPS were synthesized by a micro-emulsion process and then 0.5 to $2.5 \mathrm{wt}$.\% of nPS were reinforced into VR on a two roll mill followed by compression moulding. Physico-mechanical (tensile strength, elongation at break and young's modulus, swelling index) properties of nPS-VR blends were studied. The extent of nPS dispersion in the VR matrix and their surface morphology were observed by scanning electron microscopy, while the crystallinity and curing rate were studied by X-ray diffractometer and mooney viscometer, respectively. Optimum amount (2.5wt\%) of nPS in VR blend showed an increment of 30\% in tensile strength, $89 \%$ in young's modulus and $6 \%$ in hardness, decrement of $29 \%$ in elongation at break and $36 \%$ in swelling index as compared to pristine VR. The improvement in physico-mechanical properties was due to crosslinks of nPS in VR by curing agent, the uniform dispersion and incorporating network of nPS in the VR blend.
\end{abstract}

Keywords: Viton rubber; Nanopolystyrene; Blends; Swelling index; Mechanical properties

\section{Introduction}

Various polymer nanoparticles have been used to anlayze their effect on various properties such as mechanical, physical, thermal, mechano-chemical and curing behaviour of polymer and rubber-based nanocomposites and blends [1-4]. Polymer nanoparticles, such as nanopolystyrene (nPS), [2-9] have been synthesized by various emulsion polymerization approaches [2], such as seeded micro-emulsion [4], in-situ emulsion polymerization, atomized micro-emulsion $[2,7,10,11]$, micro-emulsion polymerization $[2,4,5,8,12-15]$ with drop wise addition of monomer and other novel methods. Micro-emulsion polymerization has received much attention and it can be scaled up at the industrial level because of optimum use of surfactant [2] in micro-emulsion polymerization as compared to the conventional emulsion polymerization [6]. The polymer nanoparticles have been used in paints, coatings, ceramic processing, agrochemical, surface treatment and biomedical sectors [2-15].

A uniform dispersion of nanomaterials shows better thermal, mechanical and physical properties [5], because the performance of polymer nanocomposites and blends is strongly dependent on the morphology of the polymer nanoparticles dispersed in the rubber matrix. The effect of polymer nanoparticles on rheological, thermal, and mechanical properties of linear low-density polyethylene was also studied [9]. The nPS structures have been incorporated to improve the mechanical properties of the polymer and rubber blends, such as polypropylene [2,5], nitrile-butadiene rubber [4], natural rubber [6], styrene-butadiene rubber, and other elastomers $[7,8]$. Curing is an important parameter which influences the mechanical, thermal and physical properties of elastomeric materials. These properties of rubber depend on the filler as well as the state of curing. The energy consumed during processing and vulcanization of rubber is directly linked to the cost of final products. The vulcanization of rubber involves multiple and complex reactions with the addition of various ingredients, which show varied thermal and mechanical properties. So, before compounding and vulcanization of rubber, it is essential to evaluate the rate of curing as well as the thermal, rheological behaviour, and physico-mechanical properties of the elastomer blend for optimization of both process as well as cost reduction $[1,4-8,16,17]$. 
Fluoroelastomer based materials are used for 0-rings, gaskets, shaft seals, fuel hose, in aerospace, offshore, energy and automobile applications owing to their chemical resistant nature. Viton is a synthetic rubber and fluoroelastomer (FE). Viton is a terpolymer of hexafluoro-propylene, vinylidene fluoride and tetra-fluoroethylene with a cure site monomer. It is a peroxide cure, $70 \%$ fluorine FE [1,1622]. In our earlier work [1], thermal, mechanical and morphological properties of surface modified montmorillonite-reinforced viton rubber (VR) nanocomposites have been studied [1,21]. Various research works have been carried out to study structure-property relationship and the different properties (melt processing, thermal, curing properties) of VR-clay based nanocomposites. Most of VR based nanocomposites have been prepared by melt mixing process [1,16-22].

The main aim of this research work is to analyze the synergism of nPS with VR matrix and synergistic effect on physical, mechanical properties and curing behaviour of nPS-VR blends. In this work, micro-emulsified nPS from 0.5 to $2.5 \mathrm{wt}$.\% were reinforced into VR by two roll mills followed by a compression moulding. Physicomechanical (tensile strength, elongation at break and young's modulus, swelling index) properties of nPS-VR blends were studied. The extent of nPS dispersion in the VR matrix and their surface morphology were studied by scanning electron microscopy, while the crystallinity and curing rate were studied by X-ray diffractometer and mooney viscometer, respectively.

\section{Experimental}

\section{Material}

Chemicals such as styrene (as monomer), sodium dodecyl sulphate (SDS as a surfactant), n-pentanol (as a co-surfactant), ammonium persulphate (APS, as initiator) and methanol were procured from S.D. Fine chemicals Ltd., (Mumbai, India). Toluene and $\mathrm{MgO}$ (acts as an acid scavenger) were received from the Merck Specialities India Limited, (Mumbai, India). VR (specific gravity=1.7) , a class of elastomer family comprising terpolymer of vinyldiene fluoride, hexafluoropropylene and tetrafluoroethylene, and Diak-3 ( $N, N$-Dicinnamylidene-1, 6-hexanediamine) as curing agent were received from DuPont Performance Elastomers, USA. As per data sheet, VR (containing fluorine $=67 \%$, carbon black $=30 \%$, high activity $\mathrm{MgO}=3 \%$ ) has a mooney scorch viscosity of 30 at 121 ${ }^{\circ} \mathrm{C}$, minimum viscosity of $0.9 \mathrm{~kg} \cdot \mathrm{cm}$, scorch time of $1 \mathrm{~min}$, maximum torque of $20.2 \mathrm{~kg} \cdot \mathrm{cm}$ and optimum cure time of $5 \mathrm{~min}$. These conditions were measured using micro die at temperature of 177 ${ }^{\circ} \mathrm{C}$.

\section{Synthesis of nPS by micro-emulsion process}

The nPS were prepared by a micro-emulsion polymerization process. In this method, $4 \mathrm{~g}$ of SDS and $0.5 \mathrm{~g}$ of APS were dissolved separately in $100 \mathrm{~mL}$ distilled water containing beakers and then stirred at 2000rpm for $30 \mathrm{~min}$ for proper mixing. In this solution, $0.5 \mathrm{~g}$ of $n$-pentanol was added and resulting mixture was transferred into the three necked round bottom flask. This reaction mixer was stirred at constant speed of $2000 \mathrm{rpm}$ for $20 \mathrm{~min}$ maintaining temperature at $75^{\circ} \mathrm{C}$. A $50 \mathrm{~g}$ of styrene was added drop wise with the help of burette. A resulting emulsion was stabilized by keeping it overnight for $12 \mathrm{~h}$ at room temperature.

The nPS were isolated by drop wise addition of methanol at constant speed of 200rpm. The beaker was kept in an ice bath to avoid the evaporation of solvent in which latex was added. Then methanol was added into this homogeneous mixture, filtered using whatman filter paper and then washed three times to remove impurities. Finally, isolated nPS were dried in hot air oven at $50 \stackrel{\circ}{\circ} \mathrm{C}$ temperature for the duration of $12 \mathrm{~h}$, which yielded $75 \% \mathrm{nPS}$.

\section{Preparation of nPS: VR blends}

The filler (i.e. nPS) in 0.5, 1.0, 1.5, 2.0 and 2.5 wt.\% of VR was mixed separately in VR. Each set masticated on a two-roll mill for $5 \mathrm{~min}$. As milling with two rolls generally produces heat, and as a result the temperature of the soft VR blend sheet rises. The temperature of sheet was found to increase up to $\sim 60{ }^{\circ} \mathrm{C}$ due to shearing and mechano-chemical breaking of the chains. In these conditions, deformations and coalescence of the nPS may occur due to this shearing phenomenon, which also affect shape of nPS blended in VR matrix. After complete mixing of nPS with VR for $30 \mathrm{~min}, 1.8 \mathrm{~g}$ of $\mathrm{MgO}$ was added as additive followed by addition of Diak-3 as curing agent. Further mastication was done for $10 \mathrm{~min}$ to disperse nPS, additives and curing agent uniformly in VR. The compounded nPS: VR rubber blend was compressed for a duration of $30 \mathrm{~min}$ at $125^{\circ} \mathrm{C}$ under pressure of $9.80 \mathrm{MPa}$ in compression moulding machine, which gave a cured nPS: VR blend sheet having size of $(13 \times 13 \times 0.2) \mathrm{cm}$.

\section{Characterization}

SEM analysis: The particle shape and structure of nPS as well as surface morphology of cured and uncured nPS: VR blends were observed by FE-SEM (Model S-4800 Type II Hitachi High Technology Corporation Limited, Japan) at an operation voltage of $10 \mathrm{keV}$ and a pressure of $0.00133 \mathrm{~kg} / \mathrm{cm}^{2}$. The samples were gold coated before analysis.

Particle size analysis: Particle size analysis was carried out by particle size analyser (MALVERN 2S90, England, UK) at system temperature of $25^{\circ} \mathrm{C}$, then the light could scatter from the sample for duration of $1 \mathrm{~min}$ at count rate speed of 237 and $228.7 \mathrm{kcps}$. Approximately, $5 \mathrm{~mL}$ of sample was taken in disposable cuvette to carry out size analysis. The particle size distribution (PSD) and $\mathrm{Z}$-average of nPS in the nanometer range were analyzed from the results and plots obtained from the software installed in the computer system.

X-ray diffraction (XRD): XRD analysis of all nPS: VR blends were conducted on Advance X-ray diffractometer (D8, Brukers, Germany) with $\mathrm{CuK} \alpha 1$ radiation $(\lambda=1.5404 \AA)$ within the $2 \theta$ range of $20-80^{\circ}$. The $\%$ crystallinity values were recorded and reported from XRD data obtained from the software installed in a computer system.

\section{Tensile test}

Tensile tests of nPS: VR blend having a rectangular shape $(6 \times 1.25 \times 0.2) \mathrm{cm}$ specimens were performed using Universal Testing 
Machine (INSTRON 5582, Buckinghamshire, UK). The tensile tests were conducted according to ASTM D638. Testing was carried out at room temperature with the crosshead speed of $0.4 \mathrm{~cm} / \mathrm{min}$. For a span length of $4 \mathrm{~cm}$, load of $500 \mathrm{~kg}$ was applied to develop tensile force. Total five specimens were tested, and the average values of tensile strength and tensile modulus were reported.

\section{Hardness}

The hardness tests were conducted by shore hardness (ASTM D2240 A-type) tester. Specimens of nPS: VR blends were tested. The average thickness of the specimen was kept $0.2 \mathrm{~cm}$, because the die for making a sheet was $0.2 \mathrm{~cm}$ in depth. Thickness was measured by thickness gauge meter. Total five specimens were tested, the average values of the results were reported.

\section{Swelling behavior}

Swelling behavior of nPS: VR blends, rectangular shape $(5 \times 1 \times 0.2) \mathrm{cm}$ specimens, were performed by toluene absorption tests as per ASTM D570 procedure. The weights of specimens were measured before immersion and then after immersion in the toluene bath for the duration of $24 \mathrm{~h}$. The condition of toluene bath was maintained at a temperature of $25{ }^{\circ} \mathrm{C}$. The specimens were removed from toluene bath after predetermined interval of time (duration of 24h). The swelling behavior was analyzed from the calculation of \% swelling or Swelling index, i.e. toluene absorption by different composition of nPS: VR blends. \% Swelling of the nPS: VR blends was calculated by equation (1) in which $W_{0}$ is the weight of the samples before soaking in toluene and $\mathrm{W}_{\mathrm{t}}$ is the weight of the samples after soaking in toluene after $24 \mathrm{~h}$.
Toluene absorption or Swelling index (\% $\left.\begin{array}{lll}\% & \text { Swelling }\end{array}\right)=$ $\left(\frac{W_{t}-W_{0}}{W_{0}}\right) \times 100$

\section{Mooney viscosity measurement}

The curing rate was determined with the help of mooney viscometer (MV-2202, Mumbai, India). A specimen of a rectangular shape $(6 \times 1.25 \times 0.2) \mathrm{cm}$ was placed on the rotor in the mooney viscometer for the duration of $45 \mathrm{~min}$ at a temperature of $125{ }^{\circ} \mathrm{C}$ and then mooney viscosity values were recorded.

\section{Results and Discussion}

\section{Surface and size analysis}

Structure and shape of nPS: The FE-SEM micrographs of microemulsified nPS are shown in Figure 1a \& 1b. The shape of microemulsified nPS are clearly observed as a needle like nanostructures having one end broader and another pointed end. However, the needle like nanostructures of the nPS are observed to be coming out on a broken surface of VR due to the cross links formed by the curing agent Diak-3 ( $N, N$-Dicinnamylidene-1, 6-hexanediamine) [16]. This could be due to the high stirring speed that may result in tubular form of micelles. These needles like nPS nanostructures Figure 1c are responsible for the anisotropic nature of VR blends, which indicates that the nPS, with high aspect ratio, could act as a reinforcing agent to provide higher mechanical properties to the VR matrix.
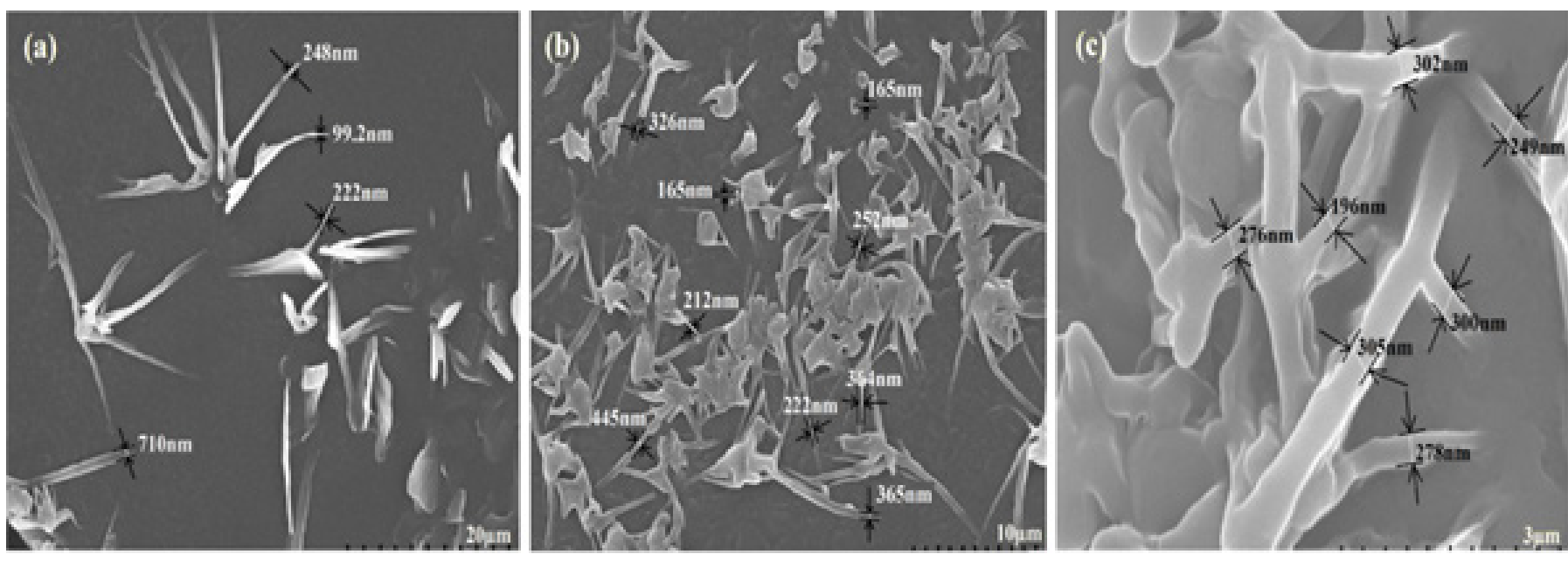

Figure 1: FE-SEM micrographs of nPS prepared by emulsion polymerization.

Size analysis of nPS: The size (i.e. diameter) of nPS was recorded by particle size analyser, and the values obtained from paricle size analyser results are reported in Table 1 . Figure 2a shows bimodal distribution curves and it also shows the two different PSDs which are almost equally broad. The intensity of peak 1 and peak 2 was reported as 47 and $53 \%$, respectively. A bimodal particle size distribution was observed due to the presence of small and large nPS needle shaped nanostructures grown during the micro- emulsion process. The range is shown by mid of peak height, i.e. $39 \mathrm{~nm}$ for peak 1 and $537 \mathrm{~nm}$ for peak 2 . An average size of the nPS nanostructures, present on the volume basis, was reported to be $274 \mathrm{~nm}$. As shown in Table 1, the polydispersity index was recorded to be 0.84 , while the $Z$-average (also known as the mean value of the particle size) was recorded as $253 \mathrm{~nm}$. Figure $2 \mathrm{~b}$ shows $\%$ number of nPS nanostructures which have size in nm, i.e. $25 \%$ of total of nPS nanostructures had an average size less than $100 \mathrm{~nm}$. 

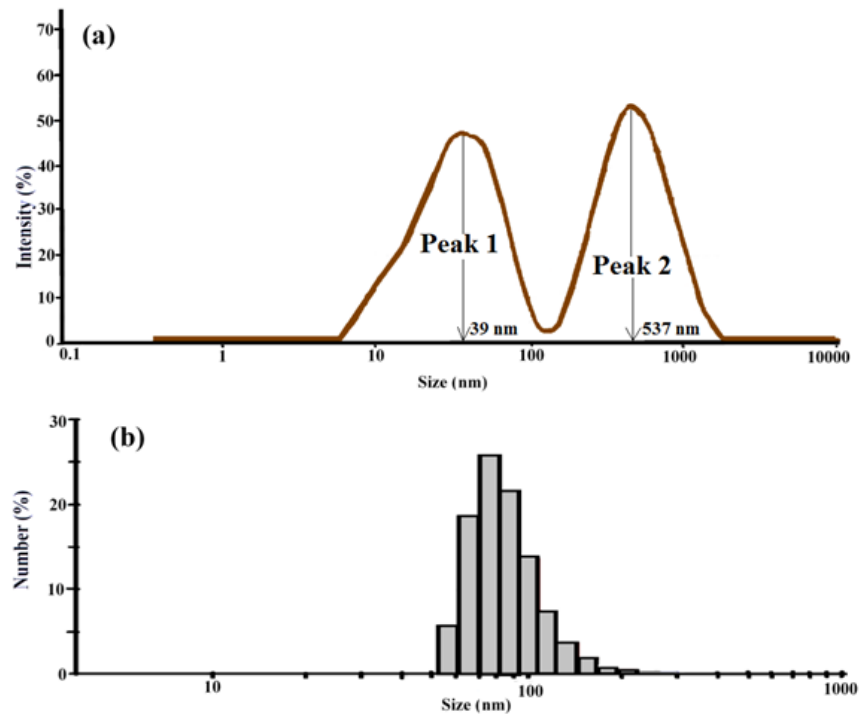

Figure 2: Particle size distribution shown by two peaks indicates (a) Intensity of a bimodal distribution curves of nPS, (b) \% number of nPS present having size in $\mathrm{nm}$.

Table 1: Particle size distribution of nPS with narrow PSD.

\begin{tabular}{|c|c|c|}
\hline Measuring Parameters & \multicolumn{2}{|c|}{ Reported Values of nPS } \\
\hline $\begin{array}{c}\text { Z-average size or } \\
\text { Average particle, (nm) }\end{array}$ & \multicolumn{2}{|c|}{253} \\
\hline PDI & \multicolumn{2}{|c|}{0.84} \\
\hline Intercept & \multicolumn{2}{|c|}{0.89} \\
\hline Peak No. & 537 & 2 \\
\hline Size, (nm) & 47 & 39 \\
\hline Intensity, (\%) & 272 & 23 \\
\hline Width, (nm) & & \\
\hline
\end{tabular}

\section{Surface morphology of uncured and cured nPS: VR} blends

FE-SEM micrographs of nPS: VR blends were recorded before and after their curing. Cross sections of broken surface of cured and uncured nPS: VR samples were observed and analyzed by FE-SEM.
It is clearly observed from Figure 3a that the uncured nPS: VR blend sheet showed slightly non-uniform overlapped layers of the rubber chains within the VR. FE-SEM micrographs of cured nPS: VR blends are shown in Figure 3b-3g. These FE-SEM micrographs show marks of needle shaped nanostructures of the nPS at the plane surface of the VR chains. However, the needle like nanostructures of the nPS might be due to the crosslinking by the curing agent Diak-3 $(N, N$ -Dicinnamylidene-1, 6-hexanediamine) [16]. These nanostructrues can clearly be seen in FE-SEM micrographs of 2.5wt. \% loaded nPS: VR blend (Figure 3h-j). Agglomerated structures were observed more as the amount of nPS increased in VR blend. Thus, it can be said that an improvement in interaction between nPS and VR is achieved at the optimum loading of nPS in VR. The nPS were properly incorporated in VR matrix despite agglomeration. This can also be strengthened from FE-SEM micrographs (Figure $3 b-j$ ), which illustrates the incorporated nPS with branched network and high aspect ratio.
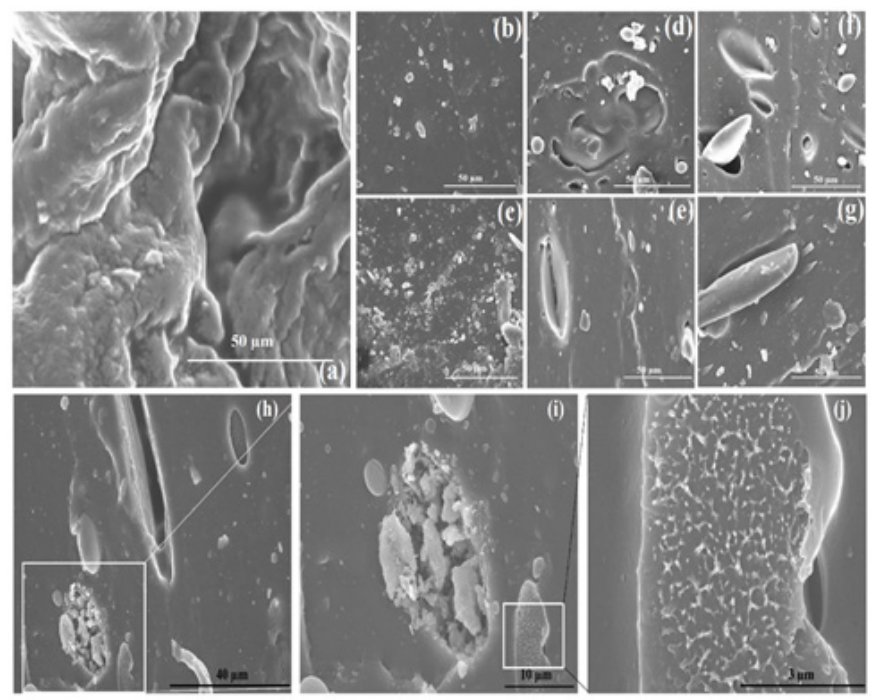

Figure 3: FE-SEM (50um resolution) micrographs of (a) uncured nPS: VR blends; (b) 0, (c) 0.5, (d) 1, (e) 1.5, (f) 2 and (g) $2.5 \mathrm{wt} \%$ of nPS in cured VR blends, (h-j) cross links points of $2.5 \mathrm{wt} \%$ of nPS in cured VR blends observed in magnified view. 
Polystyrene nanoparticles incorporated in Viton Rubber

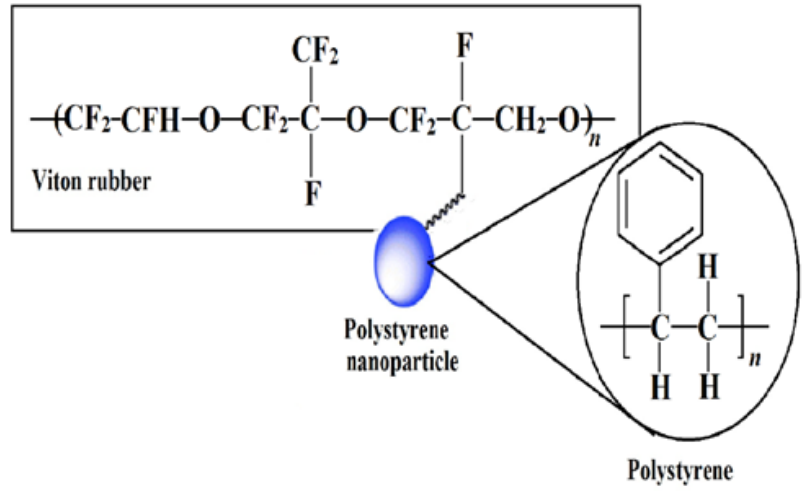

Figure 4: Structure of nPS incorporated in VR blends.

Figure 4 shows a possible structure of nPS incorporated in the VR rubber comprising terpolymer of vinyldiene fluoride, hexafluoropropylene and tetrafluoroethylene. The basic character of any amine present in Diak-3 (curing agent) is to initiate dehydrofluorination at the vinyldiene fluoride site followed by the amine

\section{Crystallinity of nPS: VR blends}

addition (cross links) in VR matrix [16]. The amine cure system shows some popularity as it enhances rubber-to-metal bonding, whereas the cross links of hexamethylene (Dicinnamylidene present in Diak-3) provides strength, and as a result it improves the mechanical properties of the resulting blend $[1,16]$.

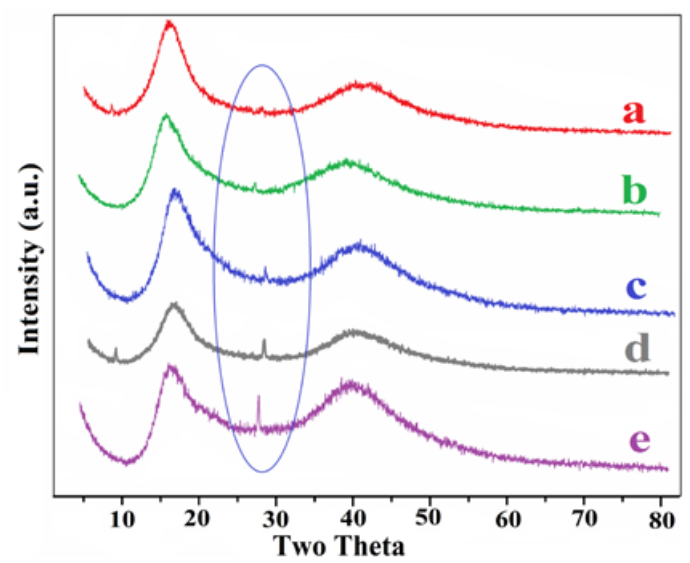

Figure 5: X-ray diffractograms of cured VR blends having (a) 0.5 , and (b) 1 , (c) 1.5 , (d) 2 and (e) $2.5 w t \%$ of nPS.

Table 2: Effect of nPS loading on the crystallinity, curing rate, mooney viscosity and swelling index of nPS: VR blends.

\begin{tabular}{|c|c|c|c|c|c|c|}
\hline $\begin{array}{l}\text { Loading of nPS } \\
\text { (wt.\%) }\end{array}$ & $\begin{array}{c}\text { Minimum } \\
\text { viscosity }(\mu)\end{array}$ & $\begin{array}{c}\text { Maximum } \\
\text { viscosity }(\mu)\end{array}$ & Cure Time (min) & Cure Index $(\mu)$ & $\begin{array}{c}\text { Crystallinity } \\
\text { (\%) }\end{array}$ & $\begin{array}{l}\text { Swelling Index } \\
\text { after } 24 \mathrm{hr}(\%)\end{array}$ \\
\hline 0.0 & 2 & 30 & 38 & 28 & - & 22 \\
\hline 0.5 & 0.50 & 36 & 33.5 & 35.5 & 20.0 & 22 \\
\hline 1.0 & 0.30 & 19 & 35 & 18.7 & 24.9 & 20 \\
\hline 1.5 & 0.20 & 24 & 35 & 23.8 & 30.7 & 18 \\
\hline 2.0 & 0.30 & 24 & 36 & 23.7 & 31.0 & 17 \\
\hline 2.5 & 0.30 & 12 & 26.25 & 11.7 & 34.8 & 14 \\
\hline
\end{tabular}

Figure 5 shows XRD patterns of the different nPS: VR blends. The crystallinity values were recorded during XRD characterization, which indicates an increasing order with increase in wt. \% of nPS in VR blends, as reported in Table 2. The increment in the crystallinity of nPS: VR blend was due to the increasing amount of crystalline nPS in the VR matrix. The high shearing of VR (having high viscosity) during two roll mixing coupled with small amount of interaction between nPS and VR might have resulted in a formation of crosslinked structures [16,17]. The XRD pattern of nPS in all VR blends exhibited at $2 \theta=\sim 27.2^{\circ}$ which became broad as nPS loading increased in VR. The XRD pattern of VR exhibited at $2 \theta=17.2^{\circ}$ due to tetra-fluoroethylene contents in VR and $2 \theta=40^{\circ}$ due to vinylidene fluoride contents in VR [22]. 


\section{Physico-mechanical properties of nPS: VR blends}

Tensile strength: Figure 6 illustrates the effect of nPS on tensile strength at break of nPS: VR blends. It is observed that tensile strength increased with increasing the nPS loading in VR. The tensile strength of $0.5,1,1.5,2$ and 2.5 wt. \% nPS loaded in VR blends were recorded as $18.4,18.8,19.2,19.8$ and $21 \mathrm{~kg} / \mathrm{cm}^{2}$, respectively, while it was least $\left(16.5 \mathrm{~kg} / \mathrm{cm}^{2}\right)$ for pristine VR. Approximately, $\sim 30 \%$ increment was observed in tensile strength of $2.5 \mathrm{wt}$ \% nPS: VR blend as compared to pristine VR. Maiti et al. [20] reported tensile strength for VR-clay based vulcanized nanocomposites which were observed in the range of 1.72 to $4.12 \mathrm{MPa}$ (i.e. 17.54 to $42.01 \mathrm{~kg}$ / $\mathrm{cm}^{2}$ ).

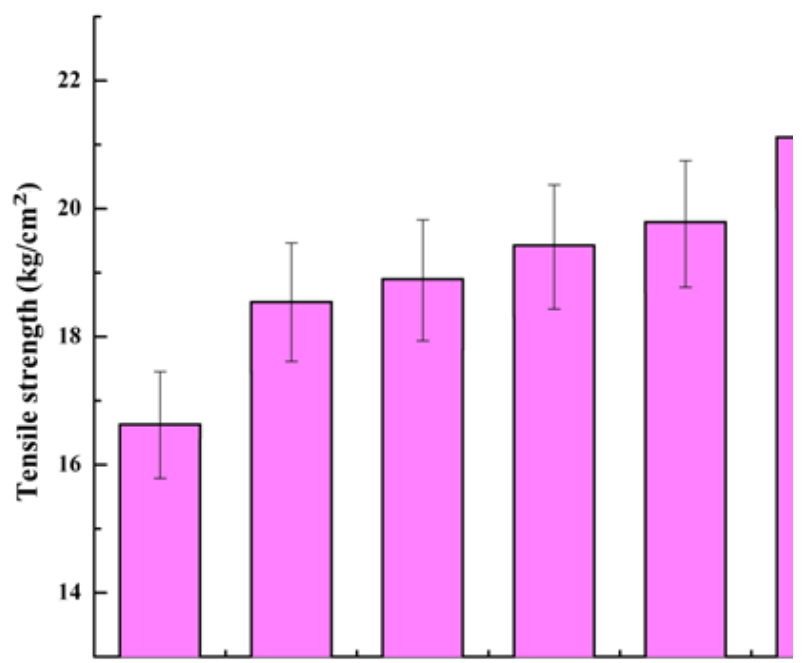

Figure 6: Tensile strength of nPS: VR blends.

Elongation at break: The effect of variation in nPS loading on \% elongation at break of nPS: VR blends are shown in Figure 7. The $\%$ elongation at break of $0.5,1,1.5,2$ and $2.5 \mathrm{wt}$. \% nPS loaded in VR were recorded as 932, 918, 837, 770, and 730\%, respectively, while it was highest up to $1025 \%$ for pristine VR. This indicates ( $29 \%$ ) decrement in \% elongation at break of $2.5 \mathrm{wt}$ \% nPS: VR blend as compared to pristine VR. The reduction in elongation at break is due the uniform dispersion of nPS having needle structures and high aspect ratio. It is also due to continuous increment in the crystallinity or highly crystalline nature of $2.5 \mathrm{wt}$. \% nPS: VR blend, which is clearly seen from X-ray diffractograms. Maiti et al. [20] reported elongation at break of different VR-clay based unvulcanized nanocomposites in the range of 80 to $1170 \%$, while elongation at break for VR-clay based vulcanized nanocomposites were observed in the range of 90 to $180 \%$.

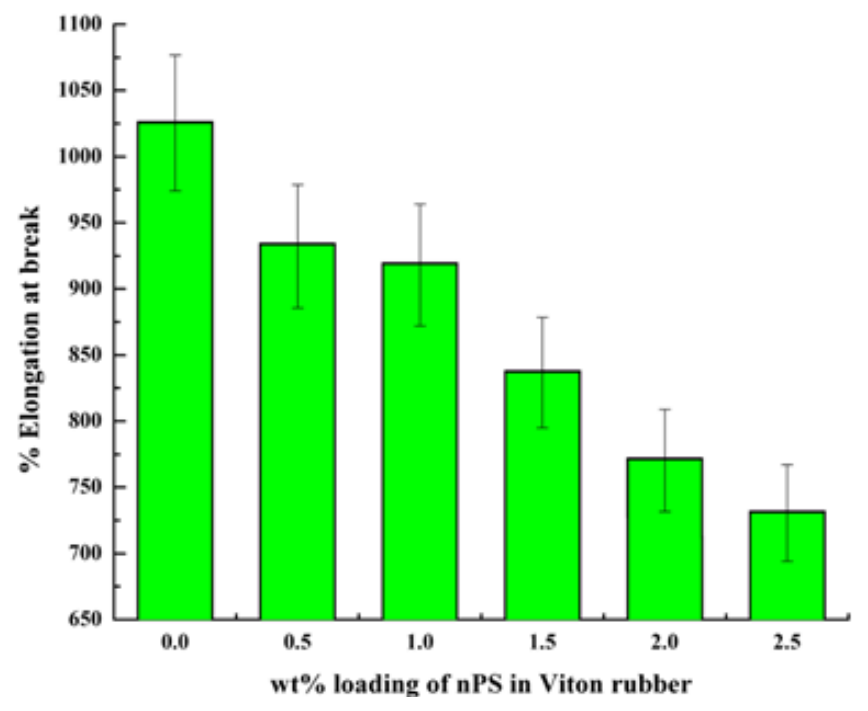

Figure 7: \% Elongation at break of nPS: VR blends.

Young's modulus: Figure 8 illustrates the effect of nPS loading (wt. $\%$ ) on Young's modulus of nPS: VR blends. The Young's modulus of $0,0.5,1,1.5,2$ and $2.5 \mathrm{wt} \% \mathrm{nPS}$ loaded in VR blends were recorded as $1.8,2.21,2.35,2.77,2.99$ and $3.4 \mathrm{~kg} / \mathrm{cm}^{2}$, respectively. It can be clearly seen from Figure 8 that Young's modulus increases with increasing nPS loading up to $2.5 \mathrm{wt} \%$, which is $89 \%$ greater as compared to pristine VR. 


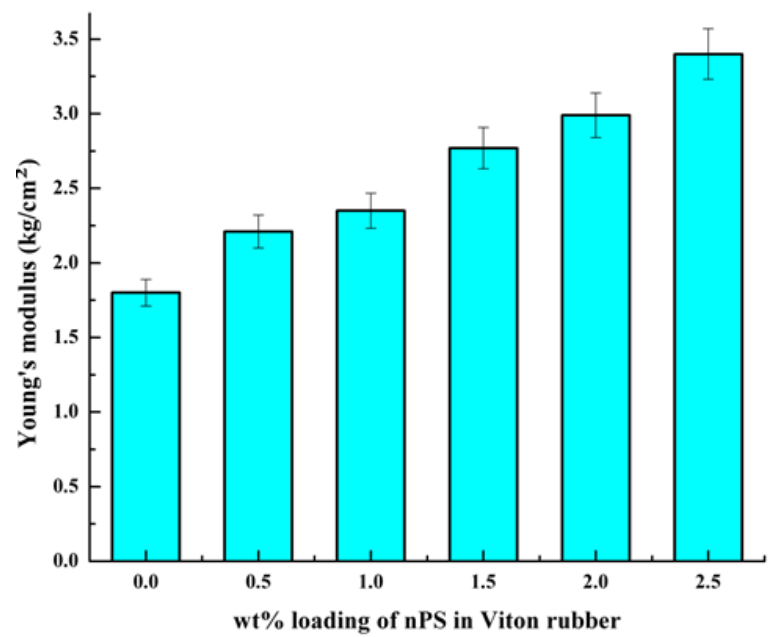

Figure 8: Young's modulus of nPS: VR blends.

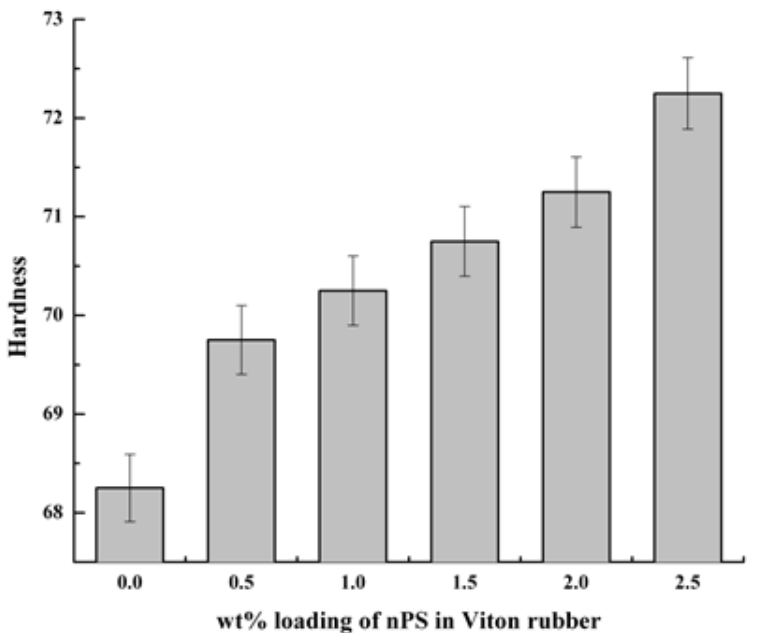

Figure 9: Hardness of nPS: VR blends.

Hardness: In case of VR blends filled with nPS, hardness was observed to be increasing continuously with increase in nPS loading up to $2.5 \mathrm{wt}$. \% in VR matrix (Figure 9). The filler made the surface of VR blend harder due to uniform distribution of nPS which might form the crosslinks due to presence of curing agent $(N, N$ -Dicinnamylidene-1, 6-hexanediamine). Thus, the addition of nPS improved the physical properties of nPS: VR blends. The hardness of $0,0.5,1,1.5,2$ and $2.5 \mathrm{wt}$. \% nPS loaded VR blends were recorded to be $68.25,69.75,70.25,70.75,71.25$ and 72.25 , respectively. Thus, 2.5wt. \% nPS added VR blends showed a marginal improvement $(6 \%)$ as compared to that of virgin VR. The improvement in hardness is due to increase in cross linking and crystallinity of the blend by addition of nPS.

Swelling index: The swelling index was reported to be decreasing with increasing the nPS wt. \% loading in VR matrix. The minimum swelling index was reported to be 14 in case of $2.5 \mathrm{wt}$. \% loaded nPS: VR blend, while the maximum swelling index was recorded to be 22 in case of pristine VR. The $36 \%$ decrement in swelling index was observed for $2.5 \mathrm{wt}$. \% nPS loaded VR blend as compared to pristine VR (Table 2). This may be due to crosslinks between nPS and VR formed by the curing agent (Diak-3) and also because of the formation of the incorporating network of nPS: VR blends which might minimize the voids inside the matrix.

\section{Effect of nPS loading on curing of VR blends}

Tables 2 shows the results of mooney viscosity and curing index along with the time required for curing. It is observed from the results that the mooney viscosity of nPS: VR blends decreased with increasing the loading of nPS from 0.5 to $2.5 \mathrm{wt}$.\% (except 1.0wt. \%) in VR matrix. The minimum mooney viscosity was observed to be $2 \mu$ in case of pristine VR, while mooney viscosity was observed to be $0.30 \mu$ in case of 2.5 wt.\% nPS filled VR blends. Mooney viscosity of the nPS: VR blends was observed to decrease to 0.50 to $0.20 \mu$ with increasing the nPS contents which is very less as compared to that of the neat VR rubber. It is due to melting the nPS in the matrix, and hence the non-monotonous effect of the nPS concentration on mooney viscosity of VR blend was also observed. Kader et al. [16] showed that the unmodified nanoclay in VR nanocomposites slowed down the cure reaction and high loading of clay in VR nanocomposites decreased the cure rate with lowering the torque [16]. 
The curing torque of pristine VR was recorded to be $30 \mu$. When $0.5 \mathrm{wt}$. \% of nPS was blended into the VR matrix, the torque was observed to be increased up to $36 \mu$. By further increasing the loading amount of nPS as 1, 1.5, 2 and $2.5 \mathrm{wt}$ \%, the values of curing torque were reported to be $18,25,24$, and $12 \mu$, respectively., It can be seen from Table 2 that the time required for curing of pristine VR matrix was $38 \mathrm{~min}$, while, the time required for curing for $0.5,1,1.5$, 2 and $2.5 \mathrm{wt}$. \% nPS loading in VR blends were recorded to be 33.5, $35,35,36$ and $26.25 \mathrm{~min}$, respectively. From the results of mooney viscosity, curing index and required curing time, it can be said that the amount of nPS plays a vital role in improving the properties of VR blend, because the higher wt. \% loading of nPS may enhance the curing process due to the uniform dispersion and incorporation of nPs in the VR blends.

\section{Conclusion}

Needle like nanostructured nPS were synthesized using microemulsion polymerization technique. The size of nPS was observed in the range of 39 to $537 \mathrm{~nm}$ having $53 \%$ intensity, and Z-average size (average size of nanostructure) was reported to be $253 \mathrm{~nm}$. Up to $2.5 \mathrm{wt}$. \% of nPS were successfully reinforced in VR matrix by a two-roll mill followed by a compression moulding. The $2.5 \mathrm{wt}$. $\%$ of nPS in VR matrix showed an improvement of $6 \%$ in hardness, $30 \%$ in tensile strength, and $89 \%$ in young's modulus; while $29 \%$ decrement in \% elongation at break and 36\% decrement in swelling index were observed as compared to pristine VR. The significant improvement in properties was due to the uniform dispersion of nPS with high aspect ratio in the VR matrix. It might also be due to continuous increase in crystallinity of $2.5 \mathrm{wt}$. \% nPS: VR blend. The presence of curing agent (Diak-3) formed the incorporating network in nPS: VR blends with proper cross links between them and minimized the voids inside the VR blend. Hence, the VR blends with improved physico-mechanical properties could be useful in various applications like O-rings and gaskets, cable connectors, electrical, light fittings, switch gear, space and defence industries.

\section{References}

1. Mali AD, Shimpi NG, Mishra S (2014) Thermal, mechanical and morphological properties of surface-modified montmorillonitereinforced viton rubber nanocomposites. Polym Int 63: 338-346.

2. Chatterjee A, Mishra S (2012) Novel synthesis of crystalline polystyrene nanoparticles (nPS) by monomer atomization in micro emulsion and their effect on thermal, rheological and mechanical properties of polypropylene. Macromol Res 20(8): 780-788.

3. Andujar CB, Tung LD, Thanh NTK (2010) Synthesis of nanoparticles for biomedical applications. Annu Rep Prog Chem 106: 553-568.

4. Lunov O, Syrovets T, Loos C (2011) Differential uptake of functionalized polystyrene nanoparticles by human macrophages and a monocytic cell line. ACS Nano 5(3): 1657-1659.
5. Mishra S, Chatterjee A (2011) Effect of nano-polystyrene (nPS) on thermal, rheological and mechanical properties of polypropylene (PP). Polym Adv Technol 22(12): 1547-1554.

6. Chuayjuljit S, Luecha W (2011) XSBR-NR rubber blends filled with polystyrene-encapsulated nanosilica prepared by differential microemulsion polymerization. J Elast Plast 43(5): 407-427.

7. Lu M, Zhou J, Wang L (2010) Design and preparation of cross-linked polystyrene nanoparticles for elastomer reinforcement. J Nanomater 2010: 1-8.

8. Ma S (2010) Nanostructures and properties of blends of homopolymer and elastomeric block copolymer nanoparticles. Ph.D. Thesis, Georgia Institute of Technology, Georgia.

9. Mishra S, Chatterjee A, Rana VK (2011) Polymer nanoparticles: their effect on rheological, thermal, and mechanical properties of linear lowdensity polyethylene (LLDPE). Polym Adv Technol 22(12): 1802-1811.

10. Mishra S, Chatterjee A (2011) Novel synthesis of polymer and copolymer nanoparticles by atomized micro emulsion technique and its characterization. Polym Adv Technol 22: 1593-1601.

11. Mishra S, Chatterjee A (2010) Particle size, morphology and thermal properties of polystyrene nanoparticles in micro emulsion process. Polym Plast Technol Eng 49(8): 791-795.

12. Yildiz U, Capekc I (2003) Microemulsion polymerization of styrene in the presence of macroinimer. Polym 44(8): 2193-2200.

13. Gan LM, Chew CH, Lye I, Imae T (1991) Microemulsion polymerization of styrene. Polym Bull 25: 193-198.

14. Guo JS, El-Aasser MS, Vanderhoff JW (1989) Microemulsion polymerization of styrene. ACS Symp Series Amer Chem Soc (Washington DC), 384: 86.

15. Kaiyi L, Zhaoqun W (2007) A novel method for preparing monodispersed polystyrene nanoparticles. Front Chem China 2:17-20.

16. Kader MA, Nah C (2004) Influence of clay on the vulcanization kinetics of fluoroelastomer nanocomposites. Polym 45(7): 2237-2247.

17. Kader MA, Lyu MY, Nah C (2006) A study on melt processing and thermal properties of fluoroelastomer nanocomposites. Comp Sci technol 66: 1431-1443.

18. Heidarian J, Hassan A, Rahman NMMA (2015) Improving the thermal properties of fluoroelastomer (Viton GF-600S) using acidic surface modified carbon nanotube. Polímeros 25(4): 392-401.

19. Ganguly A, Maiti M, Bhowmick AK (2008) Structure-property relationship of specialty elastomer-clay nanocomposites. Bull Mater Sci 31(3): 455-459.

20. Maiti M, Bhowmick AK (2006) Structure and properties of some novel fluoroelastomer/clay nanocomposites with special reference to their interaction. J Polym Sci B: Poly Phy 44: 162-176.

21. Mali AD, Shimpi NG, Mishra S (2016) Property investigation of surfacemodified MMT on mechanical and photo-oxidative degradation of viton rubber composites. Polym Bull 73: 3033-3048.

22. Heidarian J, Hassan A (2014) Microstructural and thermal properties of fluoroelastomer/carbon nanotube composites. Comp Part B 58: 166174. 